\title{
Identification of Primary Medication Concerns Regarding Thyroid Hormone Replacement Therapy From Online Patient Medication Reviews: Text Mining of Social Network Data
}

\author{
So Hyun Park ${ }^{1,2^{*}}$, PharmD; Song Hee Hong ${ }^{1 *}, \mathrm{PhD}$ \\ ${ }^{1}$ Research Institute of Pharmaceutical Science, College of Pharmacy, Seoul National University, Seoul, Republic Of Korea \\ ${ }^{2}$ Korea Institute of Drug Safety and Risk Management, Drug Safety Information Office of Adverse Drug Reaction Relief, Anyang, Republic Of Korea \\ *all authors contributed equally
}

Corresponding Author:

Song Hee Hong, $\mathrm{PhD}$

Research Institute of Pharmaceutical Science

College of Pharmacy

Seoul National University

Gwanak-gu Gwanak-ro 1

Seoul,

Republic Of Korea

Phone: 82028801547

Email: songhhong@snu.ac.kr

\section{Abstract}

Background: Patients with hypothyroidism report poor health-related quality of life despite having undergone thyroid hormone replacement therapy (THRT). Understanding patient concerns regarding levothyroxine can help improve the treatment outcomes of THRT.

Objective: This study aimed to (1) identify the distinctive themes in patient concerns regarding THRT, (2) determine whether patients have unique primary medication concerns specific to their demographics, and (3) determine the predictability of primary medication concerns on patient treatment satisfaction.

Methods: We collected patient reviews from WebMD in the United States (1037 reviews about generic levothyroxine and 1075 reviews about the brand version) posted between September 1, 2007, and January 30, 2017. We used natural language processing to identify the themes of medication concerns. Multiple regression analyses were conducted in order to examine the predictability of the primary medication concerns on patient treatment satisfaction.

Results: Natural language processing of the patient reviews of levothyroxine posted on a social networking site produced 6 distinctive themes of patient medication concerns related to levothyroxine treatment: how to take the drug, treatment initiation, dose adjustment, symptoms of pain, generic substitutability, and appearance. Patients had different primary medication concerns unique to their gender, age, and treatment duration. Furthermore, treatment satisfaction on levothyroxine depended on what primary medication concerns the patient had.

Conclusions: Natural language processing of text content available on social media could identify different themes of patient medication concerns that can be validated in future studies to inform the design of tailored medication counseling for improved patient treatment satisfaction.

(J Med Internet Res 2018;20(10):e11085) doi: $\underline{10.2196 / 11085}$

\section{KEYWORDS}

medication counseling; social network data; primary medication concerns; satisfaction with levothyroxine treatment

\section{Introduction}

Patients with hypothyroidism are treated with the most frequently prescribed drug in the United States, levothyroxine
[1], but report poor quality of life despite the treatment [2-4]. Poor quality of life while receiving the treatment possibly reflects the different views that clinicians and patients hold toward the treatment success of thyroid hormone replacement 
therapy (THRT). Clinicians judge the treatment success based on a restored reference range of thyroid hormone in the blood. On the other hand, patients feel that the treatment is successful when they are free of symptoms such as fatigue, depression, and muscle cramps that are specific to hypothyroidism. Historically, the patient view has not been given adequate attention. Now, scientific evidence has grown for the health care community to embrace the patient-centric paradigm. Specifically for THRT, endocrinologists have come to accept the patient view following a series of studies that reported that some patients do not in fact get better on THRT, despite having a reference range of the thyroid hormone in the bloodstream. For this reason, European and American thyroid professional associations now acknowledge that patients who do not thrive on levothyroxine (T4) alone may try a combination therapy of T4 and T3 (liothyronine) [5,6]. Armour, a desiccated natural thyroid hormone, offers such a combination. A synthetic version also exists with a 4:1 mix of T4 and T3 and a more consistent composition than Armour [6,7]. However, routine use of these combinations is not recommended [8].

Studies pertaining to the patient view have mostly relied on questionnaire-based surveys that employ structured measurements of patient-reported outcomes [9-11]. Perhaps a better way to understand the patient view would be to explore an alternative source of data. Patients have begun to report their health care experiences on social networks [11]. As these reports come directly from patients with no filtering in between, they have the potential to genuinely represent patient experiences. Furthermore, they continuously accumulate on a large scale every day. A Pew Research study in 2012 reported that $61 \%$ of adults have read someone else's health experience on a social network [12]. Many health websites such as WebMD and Ask-a-Patient provide open forums for patients to post ratings and reviews regarding their medication experience [13]. These online communities have become a valuable source of information for the study of patient medication experience [14].

Recent advancement in natural language processing (NLP) has enabled researchers to analyze unstructured text data posted by patients on social networks. NLP of text content on health-related social media has helped identify myriad health topics across a wide range of demographics [15]. Specifically in the area of THRT, NLP has been used to compare the patient ratings of levothyroxine and Armour along with their respective performance potentials [13]; the authors of the comparative study had recognized that patients were dissatisfied with levothyroxine and thus aimed to document the potential superiority of Armour [13]. However, before steering patients away from levothyroxine, a study needs to be conducted fully documenting the concerns of patients being treated with levothyroxine. Our study aimed to identify the distinctive themes of patient concerns regarding levothyroxine treatment based on an alternative data source in the form of a social network to inform the importance of patient-tailored medication counseling for THRT.

The specific aims of this study were to (1) identify the distinctive themes of patient concerns regarding THRT; (2) determine whether patients have unique primary medication concerns specific to their age, gender, and treatment duration; and (3) determine the predictability of primary medication concern on patient satisfaction with THRT, controlling for age, gender, treatment duration, and rating year. The results of this study can inform the design of a patient-centric medication therapy management that accounts for concerns unique to individual patients.

\section{Methods}

\section{Study Design and Settings}

Data for this study came from patient reviews and ratings of levothyroxine posted on a social network site (WebMD) in the United States between September 1, 2007, and January 30, 2017. WebMD runs a social network service that allows patients to browse patient reviews of prescription drugs based on their medication experience and to post their own reviews. Patients wishing to post their own reviews choose ratings on a scale of 1 to 5 stars for effectiveness, ease of use, and drug satisfaction and choose a reason for taking the drug. Patients can also answer questions relating to age, sex, and treatment duration. In addition, they can provide an open-ended comment. Finally, patients are required to enter the letters of a Captcha-like picture visible on the screen to prevent illegitimate use by automated programs and indicate that they agree to abide by the WebMD terms and conditions and privacy policy.

\section{Text Mining}

Text mining required two preprocesses for building text corpora from the patient reviews. The first preprocess was cleaning, through which stop-words such as articles, numbers, punctuations, and demonstrative pronouns were removed from the text. Additionally frequently appearing but irrelevant words such as "take," "im," "cant," "dont," "thyroid," "taken," "t," “now," “takeing," “takes," “taking," “age,” “ive,” “also," "almost," "els," "else," "far," and "since" were also removed. The second preprocess was stemming, which reduced the words to their "stems." Finally, a document-term matrix consisting of words along with their frequencies appearing in all the reviews was constructed. The frequency of each word was calculated from the term frequency-inverse document frequency [16,17]. For conducting the data preprocesses and analyses, open source $\mathrm{R}$ version 3.3.2 (The R Foundation) was used.

NLP was used to automate the task of information retrieval, analysis, and prediction inherent in languages used in patient reviews. Specifically, basic NLP methods such as tokenization, stop words, and stemming were used to process the content of patient reviews using the $\mathrm{R}$ software.

Latent Dirichlet allocation (LDA) was used to automatically discover hidden topics from a set of patient reviews, each of which contained a bag of words. The algorithm treated each review as a mixture of several topics and each topic as a distribution of words. By understanding topic and word distributions among the patient reviews, hidden information in the text could be found automatically [18]. For the LDA topic modeling, the numbers to be set of initial samples to be discarded, sampling iterations, and topics were 4000, 2000, and 6 , respectively. The LDA package of the open source $\mathrm{R}$ was used as the analysis tool. 


\section{Statistical Analysis}

The frequency of each theme of patient medication concern was computed for each review and then summed for all reviews. The chi-square test was performed to test whether the distribution of themes of patient medication concerns varied with age, sex, and treatment duration. The percent distribution of themes of medication concerns was also computed for each subgroup of age, gender, and treatment duration along with their standard deviations. Statistical significance was tested at an alpha of .05. To determine the predictability of primary medication concern on treatment satisfaction, multiple linear regression analysis was conducted, controlling for age, sex, treatment duration, and the year the rating was posted.

\section{Results}

\section{Description of Patient Medication Reviews}

The total number of patient medication reviews and ratings posted on WebMD collected for this study was 2112, which included 1037 reviews of levothyroxine and 1075 reviews of its brand version, Synthroid. After eliminating those that had no comments, the number decreased to 1768 (Table 1). While the reviews were mostly posted by patients themselves $(1694 / 1768,95.81 \%)$, in rare cases $(27 / 1768,1.53 \%)$ they were posted by caregivers. Interestingly, almost half of the reviews $(772 / 1768,43.67 \%)$ were posted by those who had taken the drug for less than a year. Regarding the reason for taking the drug, underactive thyroid $(1300 / 1768,73.53 \%)$ was the most common, followed by thyroid cancer $(115 / 1768,6.50 \%)$. Females (1485/1768, 83.99\%) exceeded males (214/1768, $12.1 \%$ ) with respect to posting of reviews. As for the age of the reviewers, the 45- to 64-year-old group was the most dominant (863/1768, 48.81\%). The reviews were posted between 2007 and 2017 with the largest number $(351 / 1768,19.85 \%)$ posted in 2009, followed by $2010(321 / 1768,18.16 \%)$ and 2011 $(234 / 1768,13.24 \%)$. Since 2011 , posts had a steadily declining trend.

\section{Identification of Distinctive Themes of Patient Medication Concerns}

The LDA topic modeling of the patient reviews produced 6 distinctive topics, each of which captured a hidden theme of patient medication concern (Table 2). Each hidden theme identified was given a name representing a certain aspect of medication treatment based on the top 20 most frequently appearing words [19]. A gallery of word clouds lists a complete set of words contained in each theme (Multimedia Appendix 1). The theme of patient medication concern about how to take the drug was named based on the keywords "work," "time," "hour," "dose," "water," and "morning." This concern had the least frequency share $(300 / 2194,13.67 \%)$; that is, it appeared least frequently out of the 6 themes of medication concerns. Likewise, the remaining 5 themes of patient medication concerns (treatment initiation, dose adjustment, symptoms of pain, generic substitutability, and appearance) were identified from scouting the list of top 20 keywords. The appearance theme of patient medication concern was named after scouting the keywords of "weight gain," "hair loss," and "dried skin." The theme of appearance arose most frequently (436/2194, 19.87\%), followed by dose adjustment $(396 / 2194,18.05 \%)$ and symptoms of pain $(379 / 2194,17.27 \%)$. The dose adjustment theme had keywords like "mcg," "dosage," "increase," "change," and "removal" in the list of top 20 words. The symptoms of pain theme had words like "severe," "bad," "pain," "symptom," "headache," "heart," "bodies," "muscle," "fatigue," and "leg" in the list. Treatment initiation had keywords like "feel," "just," "better," "start," "sleep," "first," and "time" in the list. Generic substitutability had keywords like "synthroid," "generic," brand," "blood," and "test."

\section{Uniqueness of Primary Medication Concerns Among Different Patients}

It was of interest to determine whether patients had unique medication concerns regarding levothyroxine treatment specific to their gender, age, and treatment duration. First, for gender, female patients mentioned "appearance" (mean 21.18\% [SD $0.41]$ ) as the most frequent concern (or primary medication concern) and how to take the drug (mean $12.69 \%$ [SD 0.33]) as the least frequent concern (Figure 1). However, male patients were least concerned about appearance (mean 13.06\% [SD $0.34]$ ) and most concerned about symptoms of pain (mean $19.93 \%$ [SD 0.40]).

Patient medication concerns regarding dose adjustment, symptoms of pain, and appearance were quite different according to age. The youngest (13 to 44 years) were the most concerned about dose adjustment (mean 21.33\% [SD 0.41]) and appearance (mean $21.03 \%$ [SD 0.41]) while the oldest (65 years and older) were most concerned about symptoms of pain (mean $22.39 \%$ [SD 0.42]). Patient medication concerns were also quite different with treatment duration. Patients on levothyroxine less than a year were more concerned about appearance (mean $21.64 \%$ [SD 0.41]) and drug therapy initiation (mean $19.33 \%$ [SD 0.39]) while patients on levothyroxine 5 years or longer were more concerned about how to take the drug (mean $18.96 \%$ [SD 0.39]), dose adjustment (mean 20.70\% [SD 0.41]), and generic substitutability (mean $19.75 \%$ [SD 0.40]). 
Table 1. Characteristics of patient medication review writers.

\begin{tabular}{|c|c|}
\hline Demographics & Total $(\mathrm{n}=1768), \mathrm{n}(\%)$ \\
\hline \multicolumn{2}{|l|}{ Gender } \\
\hline Male & $214(12.10)$ \\
\hline Female & $1485(83.99)$ \\
\hline N/A & $69(3.90)$ \\
\hline \multicolumn{2}{|l|}{ Age, years } \\
\hline $13-44$ & $562(31.79)$ \\
\hline $45-64$ & $863(48.81)$ \\
\hline 65 and over & $306(17.31)$ \\
\hline N/A & $37(2.09)$ \\
\hline \multicolumn{2}{|l|}{ Treatment duration, years } \\
\hline Less than 1 & $772(43.67)$ \\
\hline $1-5$ & $423(23.93)$ \\
\hline More than 5 & $505(28.56)$ \\
\hline N/A & $68(3.85)$ \\
\hline \multicolumn{2}{|l|}{ Reasons of taking levothyroxine } \\
\hline Progressive disease of the thyroid gland & $56(3.17)$ \\
\hline Additional treatment for thyroid cancer & $1(0.06)$ \\
\hline Decreased thyroid function existing from birth & $20(1.13)$ \\
\hline Enlarged thyroid gland & $42(2.38)$ \\
\hline Myxedema coma & $1(0.06)$ \\
\hline Serious decrease in thyroid function & $81(4.58)$ \\
\hline Thyroid cancer & $115(6.50)$ \\
\hline Underactive thyroid & $1300(73.53)$ \\
\hline Other & $152(8.60)$ \\
\hline \multicolumn{2}{|l|}{ Reviewer type } \\
\hline Caregiver & $27(1.53)$ \\
\hline Patient & $1694(95.81)$ \\
\hline N/A & $42(2.66)$ \\
\hline \multicolumn{2}{|l|}{ Year } \\
\hline 2007 & $73(4.13)$ \\
\hline 2008 & $210(11.88)$ \\
\hline 2009 & $351(19.85)$ \\
\hline 2010 & $321(18.16)$ \\
\hline 2011 & 234 (13.24) \\
\hline 2012 & $178(10.07)$ \\
\hline 2013 & 197 (11.14) \\
\hline 2014 & $107(6.05)$ \\
\hline 2015 & $39(2.21)$ \\
\hline 2016 & $54(3.05)$ \\
\hline 2017 & $4(0.23)$ \\
\hline
\end{tabular}


Table 2. Identification of 6 distinctive themes of patient medication concerns about levothyroxine from patient reviews.

\begin{tabular}{|c|c|c|}
\hline Theme name & Top 20 words & Frequency $\left(\mathrm{n}=2194^{\mathrm{a}}\right), \mathrm{n}(\%)$ \\
\hline How to take the drug & $\begin{array}{l}\text { work, will, can, dose, help, time, eat, need, use, life, one, well, hour, good, know, thing, } \\
\text { morning, anything, people, levothyroxine }\end{array}$ & $300(13.67)$ \\
\hline Treatment initiation & $\begin{array}{l}\text { feel, day, like, get, just, better, week, start, much, medicine, want, sleep, make, pill, first, } \\
\text { night, know, think, time, keep }\end{array}$ & $343(15.63)$ \\
\hline Dose adjustment & $\begin{array}{l}\text { medicaid, year, mcg, effect, side, dosage, increase, change, noticeable, differ, diagnose, } \\
\text { hypothyroidism, hope, little, seem, removal, two, disease, old, great }\end{array}$ & $396(18.05)$ \\
\hline Symptoms of pain & $\begin{array}{l}\text { med, drug, problem, pain, even, stop, heart, low, cause, severe, bodies, bad, fatigue, } \\
\text { headaches, anyone, worse, muscle, symptom, leg, look }\end{array}$ & $379(17.27)$ \\
\hline Generic substitutability & $\begin{array}{l}\text { synthroid, doctor, back, level, blood, test, put, normal, generic, never, trial, went, right, } \\
\text { TSH, symptom, felt, told, year, said, brand }\end{array}$ & $340(15.50)$ \\
\hline Appearance & $\begin{array}{l}\text { weight, gain, month, hair, still, energized, tired, loss, start, see, lbs, time, lost, depressant, } \\
\text { lose, always, skin, pound, dried, fall }\end{array}$ & $436(19.87)$ \\
\hline
\end{tabular}

${ }^{\text {a }}$ Total number of primary themes represented in each review. This is greater than the total number of reviews (1768) because some reviews had more than one theme tied for the primary concern.

Figure 1. Primary medication concerns unique to patients of different backgrounds.

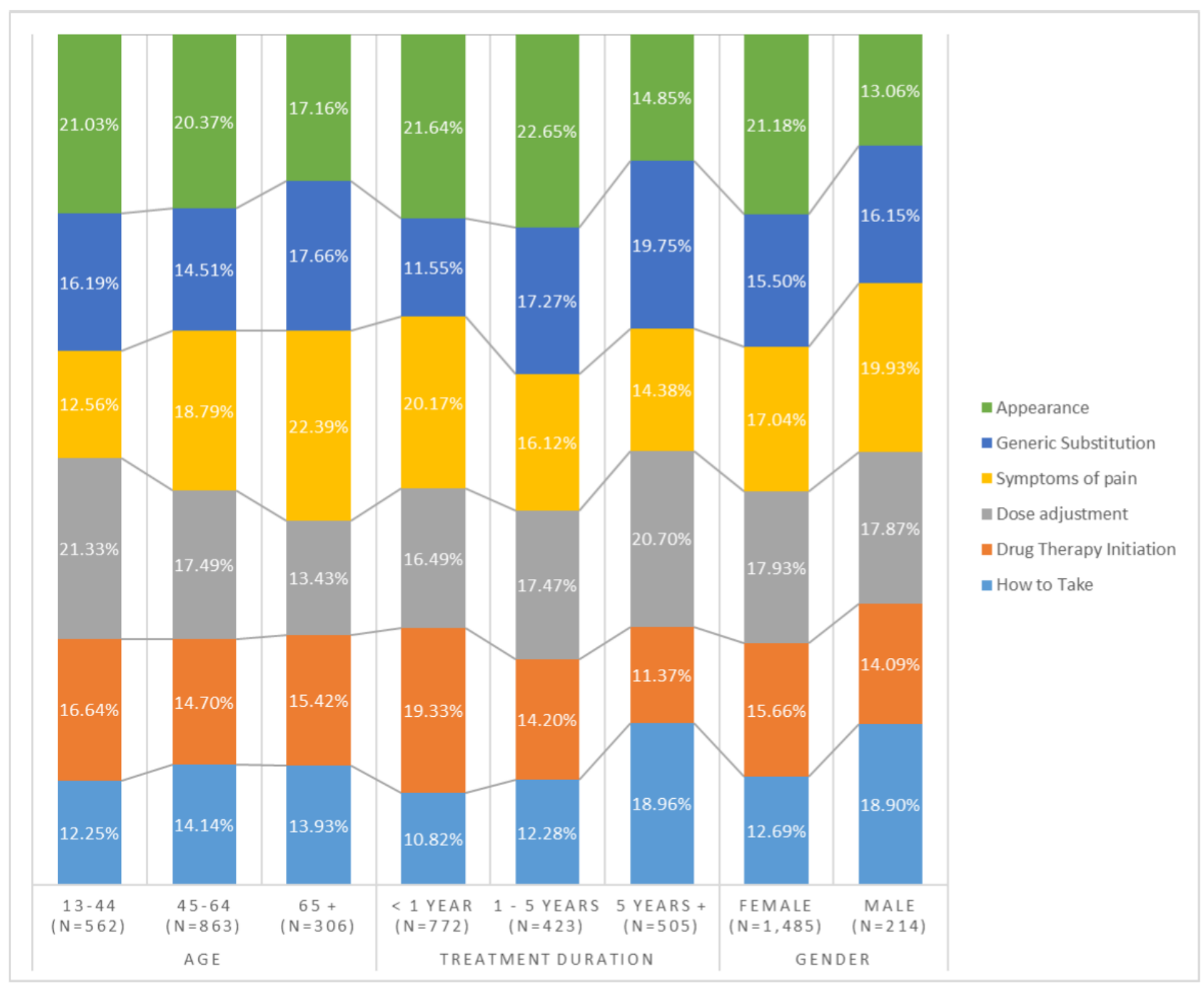


Table 3. Multiple regression analysis on factors affecting satisfaction score.

\begin{tabular}{|c|c|c|c|}
\hline Characteristics & Coefficient $(\beta)$ & Standard error & $P$ value \\
\hline Intercept & 3.11 & 0.12 & $<.001$ \\
\hline \multicolumn{4}{|l|}{ Primary medication concern } \\
\hline Appearance (reference) & - & - & - \\
\hline How to take the drug & 0.68 & 0.12 & $<.001$ \\
\hline Treatment initiation & -0.03 & 0.11 & .81 \\
\hline Dose adjustment & 0.44 & 0.11 & $<.001$ \\
\hline Symptoms of pain & -0.29 & 0.11 & .01 \\
\hline Generic substitutability & 0.11 & 0.11 & .32 \\
\hline \multicolumn{4}{|l|}{ Treatment duration, years } \\
\hline More than 5 (reference) & - & - & - \\
\hline Less than 1 & -0.76 & 0.08 & $<.001$ \\
\hline $1-5$ & -0.38 & 0.10 & $<.001$ \\
\hline \multicolumn{4}{|l|}{ Age, years } \\
\hline 45-64 (reference) & - & - & - \\
\hline $13-44$ & 0.12 & 0.08 & .14 \\
\hline 65 and over & 0.03 & 0.10 & .76 \\
\hline \multicolumn{4}{|l|}{ Gender } \\
\hline Female (reference) & - & - & - \\
\hline Male & 0.24 & 0.11 & .03 \\
\hline Rating year & -0.04 & 0.02 & .01 \\
\hline
\end{tabular}

\section{Dependency of Treatment Satisfaction on Primary Medication Concerns}

The last aim of this study was to determine whether patient treatment satisfaction with THRT depends on what primary medication concerns they have, controlling for age, gender, and treatment duration. For this aim, each review's star rating of levothyroxine was treated as an interval scale rating. The 6 themes of patient medication concerns were dichotomized to indicate whether each medication concern was primary for the patient. As compared to the primary medication concern regarding appearance, the primary medication concern regarding how to take the drug resulted in a significantly better treatment satisfaction, up to as much as 0.68 , with gender, age, treatment duration, and rating year being constant (Table 3 ). In other words, when patients had how to take the drug as their primary medication concern, their treatment satisfaction with THRT was 0.68 points higher out of 5 stars compared to those patients who had appearance as their primary medication concern. Treatment satisfaction also significantly increased (by 0.44 points) for the primary medication concern dose adjustment but reduced by 0.29 points $(P=.01)$ for the primary medication concern symptoms of pain compared to the reference primary medication concern of appearance. Interestingly, treatment initiation and generic substitution did not have a significant impact on the treatment satisfaction with THRT relative to appearance.

Regarding the potential confounders controlled in the regression analysis, age did not result in any significant explanation of treatment satisfaction with THRT. For gender, male patients reported a significantly higher $(\beta=0.24, P=.03)$ treatment satisfaction than female patients. For treatment duration, the longer the treatment duration, the higher the treatment satisfaction. In other words, as compared to the reviews written by patients who had taken levothyroxine for more than 5 years, the reviews written by patients who had taken the drug for shorter durations had significantly lower levels of treatment satisfaction.

Finally, multiple regression had the variable of rating year as an explanatory variable. The rating year represents the year the review was posted. For reviews posted in more recent years, the treatment satisfaction was slightly but significantly lower than the previous years. A 1-year increase in the rating year was associated with a decline of 0.04 points $(P=.01)$ in the treatment satisfaction.

\section{Discussion}

\section{Principal Findings}

Above all, the NLP of patient medication reviews posted on a social network identified 6 distinctive themes of patient medication concerns on THRT: how to take the drug, treatment initiation, dose adjustment, symptoms of pain, generic substitutability, and appearance. Those 6 themes seem to cover all areas of medication needs of patients on THRT. The patient medication concerns on how to take the drug and dose adjustment quite well reflect the tough challenges associated 
with the task of taking levothyroxine appropriately. Levothyroxine requires scrupulous planning regarding when to take it. Many factors such as food, medications, and health conditions hamper the ability to maintain a desired range of thyroxine in the bloodstream [20]. It is critical to maintain the desired range because of the narrow therapeutic index and low absorption rate [21,22]. This study successfully identified those challenges into primary medication concerns how to take the drug and dose adjustment.

Likewise, the themes of symptoms of pain and appearance are well documented in the literature. Patients on THRT are known to complain about various symptoms of pain such as fatigue; loss of sleep; heart issues; headache; and muscle, leg, and body pain [2-4]. For this reason, a patient-reported outcomes instrument, Thyroid-Dependent Quality of Life, was developed to measure those symptoms of pain using several items on bodily discomfort [23]. Further, the most frequently mentioned medication concern was on appearance. A study reports that patients on THRT are often dissatisfied with levothyroxine treatment because of weight gain, hair loss, and dry skin [24].

Last, patients were quite frequently $(15.5 \%)$ concerned about generic substitutability. Considering the price difference between brands and generic versions, patients would certainly rather use a generic version. To help ease patient concerns on generic substitutability, in 1997 the US Food and Drug Administration made the equivalence criteria stricter, from a range of $90 \%$ to $110 \%$ before to $95 \%$ to $105 \%$ after [25-27]. However, the issue of generic substitutability is still controversial. The American Thyroid Association reports that in a small fraction of patients higher rates of adverse events were associated with changes in levothyroxine preparations [6]. Furthermore, a reformulation of Merck's Lévothyrox with different excipients to reduce variability in dosing from $90 \%$ to $110 \%$ to $95 \%$ to $105 \%$ led to a huge controversy in France in 2017 (thousands of patients made complaints about adverse effects after taking the reformulated version [28]).

Documenting the uniqueness of primary medication concerns among different patients would emphasize the importance of tailored medication counseling. This study found that primary medication concerns were unique to patients of different genders, ages, and treatment durations. Female patients had appearance as their primary medication concern while male patients mentioned how to take the drug quite often. While it is apparent that females are quite attentive to appearance, it raises the question why males are more concerned about how to take the drug. Taking levothyroxine correctly requires careful planning regarding foods and time of administration. Perhaps females are accustomed to planning these things for family members, and thus, are more confident about taking the medication correctly than males.

This study also found that the youngest patients (aged 13 to 44 years) were very concerned about dose adjustment (21.33\%) and appearance $(21.03 \%)$ while the oldest (aged 65 years and older) were most concerned about symptoms of pain (22.39\%). It is understandable that younger people were concerned about appearance. However, it requires some explanation why younger people were concerned about dose adjustment. Younger people must have just begun the levothyroxine treatment, and thus it would take longer for them to get the dose adjusted. On the other hand, older people were most concerned about the symptoms of pain because they were already suffering from many symptoms of pain resulting from aging. Patients with hypothyroidism would certainly experience symptoms of hypothyroidism unique to their age [22].

As the treatment duration became longer, patients were less concerned about appearance and treatment initiation and became more concerned about how to take the drug, dose adjustment, and generic substitution. Patients who had taken the drug for quite a while may have realized that it was more challenging to control hypothyroidism with levothyroxine. Once they realized that it is challenging, they would be more concerned about how to take the drug and dose adjustment. They would also be concerned about generic substitutability because a longer treatment duration makes it economically burdensome to take the expensive brand name drug.

Last, patient satisfaction with levothyroxine treatment depended on their primary medication concern. Patients who had the primary medication concerns of how to take the drug and dose adjustment were more satisfied with the levothyroxine medication therapy (up 0.68 and 0.44 , respectively) compared to those whose primary medication concern was appearance. Evidently, patients who were more concerned about how to get the THRT right would have achieved better treatment outcomes. On the other hand, patients who had a primary medication concern of symptoms of pain were less satisfied with THRT (down 0.29 points) than the referents. Naturally, symptoms of pain would have negatively affected treatment satisfaction.

One of the interesting study findings was that the longer the treatment duration, the higher the treatment satisfaction. Patients who had taken the drug longer were more likely to have known how to take the drug correctly with the right dose and thus to have achieved better treatment outcomes. Moreover, males were more satisfied with the treatment than females. Because males were more concerned about how to take the drug but less concerned about appearance than females, they were more likely to achieve treatment success, which leads to higher satisfaction scores.

\section{Practice Implication}

Patients with hypothyroidism had unique primary medication concerns depending on their identity. In order to improve their treatment outcomes, it is necessary to provide tailored medication counseling, specifically focusing on their primary medication concerns such as how to take the drug, dose adjustment, symptoms of pain, and appearance.

\section{Limitations}

First, the LDA algorithm used in this research is a method of automatically discovering topics or themes by using statistical principles. Therefore, although LDA is advantageous in extracting hidden themes, the scientific qualities of the themes should be further validated. Furthermore, the researchers' subjectivity might have played an important role in the process of extracting hidden themes. For example, this study set the number of themes to be extracted to 6 based on its 
manageability. However, research has yet to come up with an easy way to choose an optimal number of themes [29]. Second, there may be a bias that arises from using online reviews from social media. Considering that people are more likely to report negative views than positive ones, the patient reviews used for this study may have come from patients dissatisfied with levothyroxine. Although negative views could better reflect patient concerns, they do not represent all views on levothyroxine. It is also important to note that this study used patient reviews from only one social media platform. Data collected from multiple social media platforms would have increased representativeness. Finally, the reported themes of patient medication concerns on levothyroxine treatment may not be valid because they were based on unstructured text data directly reported from patients. While those text data have their own merits, the reported themes need to be tested for their validity in future studies.

\section{Conclusion}

NLP of the patient reviews of levothyroxine posted on a social network produced 6 distinctive themes of patient medication concerns that covered all areas of levothyroxine treatment. Patients had unique primary medication concerns specific to their gender, age, and treatment duration. Furthermore, patients' treatment satisfaction on levothyroxine varied depending on what primary medication conditions individual patients had. These results inform the design of patient-tailored medication counseling to accommodate unique primary medication concerns of individual patients [30].

\section{Acknowledgments}

We thank the Research Institute of Pharmaceutical Science, College of Pharmacy, Seoul National University for supporting this study.

\section{Conflicts of Interest}

None Declared.

\section{Multimedia Appendix 1}

Word clouds of primary medication concerns.

[PNG File, 1MB-Multimedia Appendix 1]

\section{References}

1. IQVIA Institute for Human Data Science. 2018 Apr 19. Medicines use and spending in the US: a review of 2017 and outlook to 2022 URL: https://bit.ly/2yANWMX[WebCite Cache ID 72gHXAKPi]

2. Winther KH, Cramon P, Watt T, Bjorner JB, Ekholm O, Feldt-Rasmussen U, et al. Disease-specific as well as generic quality of life is widely impacted in autoimmune hypothyroidism and improves during the first six months of levothyroxine therapy. PLoS One 2016;11(6):e0156925 [FREE Full text] [doi: 10.1371/journal.pone.0156925] [Medline: 27257805]

3. Saravanan P, Chau W, Roberts N, Vedhara K, Greenwood R, Dayan CM. Psychological well-being in patients on 'adequate' doses of 1-thyroxine: results of a large, controlled community-based questionnaire study. Clin Endocrinol (Oxf) 2002 Nov;57(5):577-585. [Medline: 12390330]

4. Wekking EM, Appelhof BC, Fliers E, Schene AH, Huyser J, Tijssen JGP, et al. Cognitive functioning and well-being in euthyroid patients on thyroxine replacement therapy for primary hypothyroidism. Eur J Endocrinol 2005 Dec;153(6):747-753. [doi: 10.1530/eje.1.02025] [Medline: 16322379 ]

5. Wiersinga WM, Duntas L, Fadeyev V, Nygaard B, Vanderpump MPJ. 2012 ETA guidelines: the use of L-T4 + L-T3 in the treatment of hypothyroidism. Eur Thyroid J 2012 Jul;1(2):55-71 [FREE Full text] [doi: 10.1159/000339444] [Medline: 24782999]

6. The ATA unveils new data to FDA on bioequivalence of levothyroxine. URL: https://www.thyroid.org/ the-ata-unveils-new-data-to-fda-on-bioequivalence-of-levothyroxine/ [accessed 2018-07-17] [WebCite Cache ID 70yBTMWma]

7. Thyroid hormone treatment. URL: https://www.thyroid.org/thyroid-hormone-treatment/ [accessed 2018-07-17] [WebCite Cache ID 70y2i1MNk]

8. Dayan C, Panicker V. Management of hypothyroidism with combination thyroxine (T4) and triiodothyronine (T3) hormone replacement in clinical practice: a review of suggested guidance. Thyroid Res 2018;11:1 [FREE Full text] [doi: 10.1186/s13044-018-0045-x] [Medline: 29375671]

9. Doyle C, Lennox L, Bell D. A systematic review of evidence on the links between patient experience and clinical safety and effectiveness. BMJ Open 2013;3(1):1 [FREE Full text] [doi: 10.1136/bmjopen-2012-001570] [Medline: 23293244]

10. Manary MP, Boulding W, Staelin R, Glickman SW. The patient experience and health outcomes. N Engl J Med 2013 Jan 17;368(3):201-203. [doi: 10.1056/NEJMp1211775] [Medline: 23268647]

11. Greaves F, Ramirez-Cano D, Millett C, Darzi A, Donaldson L. Use of sentiment analysis for capturing patient experience from free-text comments posted online. J Med Internet Res 2013;15(11):e239 [FREE Full text] [doi: 10.2196/jmir.2721] [Medline: 24184993] 
12. Fox S. The social life of health information. Washington: Pew Internet and American Life Project; 2011. URL: http://www. pewinternet.org/2011/05/12/the-social-life-of-health-information-2011/ [accessed 2018-08-09] [WebCite Cache ID 71XOmvYcf]

13. Adusumalli S, Lee H, Hoi Q, Koo S, Tan IB, Ng PC. Assessment of Web-based consumer reviews as a resource for drug performance. J Med Internet Res 2015 Aug 28;17(8):e211 [FREE Full text] [doi: 10.2196/jmir.4396] [Medline: 26319108]

14. Yang C, Jiang L, Yang H. Tang X: Detecting signals of adverse drug reactions from health consumer contributed content in social media. 2012 Presented at: Proceedings of ACM SIGKDD Workshop on Health Informatics; 2012; Beijing.

15. Sadah SA, Shahbazi M, Wiley MT, Hristidis V. Demographic-based content analysis of Web-based health-related social media. J Med Internet Res 2016 Jun 13;18(6):e148 [FREE Full text] [doi: 10.2196/jmir.5327] [Medline: 27296242]

16. Salton G, McGill MJ. Introduction to Modern Information Retrieval. New York: McGraw-Hill, Inc; 1986.

17. Hornik K, Grün B. Topicmodels: An R package for fitting topic models. J Stat Softw 2011;40(13):1-30.

18. Zhan Y, Liu R, Li Q, Leischow SJ, Zeng DD. Identifying topics for e-cigarette user-generated contents: a case study from multiple social media platforms. J Med Internet Res 2017 Jan 20;19(1):e24 [FREE Full text] [doi: 10.2196/jmir.5780] [Medline: 28108428]

19. Choi HS, Lee WS, Sohn S. Analyzing research trends in personal information privacy using topic modeling. Comput Sec 2017 Jun;67:244-253. [doi: 10.1016/j.cose.2017.03.007]

20. Bach-Huynh T, Nayak B, Loh J, Soldin S, Jonklaas J. Timing of levothyroxine administration affects serum thyrotropin concentration. J Clin Endocrinol Metab 2009 Oct;94(10):3905-3912 [FREE Full text] [doi: 10.1210/jc.2009-0860] [Medline: 19584184]

21. Gottwald-Hostalek U, Uhl W, Wolna P, Kahaly GJ. New levothyroxine formulation meeting 95-105\% specification over the whole shelf-life: results from two pharmacokinetic trials. Curr Med Res Opin 2017 Dec;33(2):169-174. [doi: 10.1080/03007995.2016.1246434] [Medline: 27718637]

22. Park KH, Lee EJ. Recent review on medical treatment of thyroid disease. J Korean Med Assoc 2012;55(12):1207. [doi: 10.5124/jkma.2012.55.12.1207]

23. McMillan CV, Bradley C, Woodcock A, Razvi S, Weaver JU. Design of new questionnaires to measure quality of life and treatment satisfaction in hypothyroidism. Thyroid 2004 Nov;14(11):916-925. [doi: 10.1089/thy.2004.14.916] [Medline: $\underline{15671770]}$

24. Levoxyl Professional Information. URL: https://www.rxlist.com/levoxyl-side-effects-drug-center.htm\#overview [accessed 2018-07-17] [WebCite Cache ID 70yBa2KZY]

25. Brent G, Koenig R. Thyroid and anti-thyroid drugs. In: Goodman \& Gilman's The Pharmacological Basis of Therapeutics, 12th Edition. New York: McGraw-Hill; 2011.

26. US Food and Drug Administration. 2018. Orange Book: Approved Drug Products with Therapeutic Equivalence Evaluations. 38th Edition URL: https://www.fda.gov/downloads/drugs/developmentapprovalprocess/ucm071436.pdf [WebCite Cache ID 71XQe8Yoe]

27. Darrel H. Current challenges in the management of hypothyroidism. US Pharmacist 2012 Jan:113-1678.

28. Casassus B. Risks of reformulation: French patients complain after Merck modifies levothyroxine pills. BMJ 2018 Dec 16;360:k714. [Medline: 29453193]

29. Zhao W, Chen JJ, Perkins R, Liu Z, Ge W, Ding Y, et al. A heuristic approach to determine an appropriate number of topics in topic modeling. BMC Bioinformatics 2015;16 Suppl 13:S8-S13 [FREE Full text] [doi: 10.1186/1471-2105-16-S13-S8] [Medline: 26424364]

30. Kalra S, Agarwal N, Aggarwal R, Agarwal S, Bajaj S, Bantwal G, et al. Patient-centered management of hypothyroidism. Indian J Endocrinol Metab 2017;21(3):475-477 [FREE Full text] [doi: 10.4103/ijem.IJEM 93 17] [Medline: 28553608]

\section{Abbreviations \\ THRT: thyroid hormone replacement therapy \\ NLP: natural language processing \\ LDA: latent Dirichlet allocation}


Edited by G Eysenbach; submitted 18.05.18; peer-reviewed by J Taylor, TH Collet; comments to author 21.06.18; revised version received 17.07.18; accepted 10.08.18; published 24.10.18

Please cite as:

Park SH, Hong SH

Identification of Primary Medication Concerns Regarding Thyroid Hormone Replacement Therapy From Online Patient Medication

Reviews: Text Mining of Social Network Data

J Med Internet Res 2018;20(10):e11085

URL: http://www.jmir.org/2018/10/e11085/

doi: $\underline{10.2196 / 11085}$

PMID: 30355555

(C) So Hyun Park, Song Hee Hong. Originally published in the Journal of Medical Internet Research (http://www.jmir.org), 24.10.2018. This is an open-access article distributed under the terms of the Creative Commons Attribution License (https://creativecommons.org/licenses/by/4.0/), which permits unrestricted use, distribution, and reproduction in any medium, provided the original work, first published in the Journal of Medical Internet Research, is properly cited. The complete bibliographic information, a link to the original publication on http://www.jmir.org/, as well as this copyright and license information must be included. 